\title{
MISCELLANY
}

\section{Preliminary Notes on the Treatment of 50 Cases of Tenosynovitis in Industry*}

\section{E. L. KNOWLES AND M. D. KIPLING \\ From Imperial Chemical Industries Limited (Billingham Division)}

The treatment of tenosynovitis in industry has been fully discussed in other papers, particularly, by Thompson, Plewes, and Shaw (1951). This paper makes no claim for a new type of treatment except in regard to the patient's capacity for work, which, as far as possible, has not been limited at all and, in our opinion, there has been a very considerable saving both in the period of disability and the time spent on light duty.

Tenosynovitis most commonly affects the wrist. In our series, in 44 of the 50 cases it involved the extensor forearm muscles, and of these in no fewer than 38 it involved the extensor carpi radialis group. The cause was nearly always a repetitive movement, particularly hammering, pulling, and sawing. In the other six cases the tibialis anticus was affected, and in at least three of these was due to direct trauma.

In the past it has been customary for all patients with tenosynovitis seen at this factory medical department to have the affected part immobilized. The condition was reviewed after a week and generally the immobilization was continued for a total of 14 days. During this period the patient was automatically restricted to light work usually of a one-handed nature. This procedure was *Received for publication April 25, 1953. unsatisfactory, the patient often suffering financially due to loss of bonus earnings, and the firm losing through employing a semi-fit man. It was therefore decided to treat a series by physiotherapy using the services of our two whole-time physiotherapists. The following basic criteria were laid down :-(1) That no case should be labelled as "tenosynovitis". unless a crepitus was palpable on movement. (Cases with local swelling and no crepitus present were excluded from the series. No record was kept of the latter but it is our opinion that they responded extremely quickly to the routine treatment.) (2) That no patient should be placed on light work unless he himself specifically requested this. As a result most of the patients continued during treatment the work which was the primary cause of their disability. (3) That no case was to be considered cured until the patient himself stated that there was no pain or limitation on movement, and that he, in his opinion, was cured. This point is mentioned since clinically, that is, as regards crepitus, swelling, and movement, many cases were considered clear some time before the patient himself was satisfied. (4) That every case taken on or discharged was to be seen by the Works Medical Officer. (5) That every patient should be warned on his first attendance that swelling and discomfort might last for the rest of the day of initial treatment and were the normal result of adequate massage.

The treatment used was that described by Cyriax

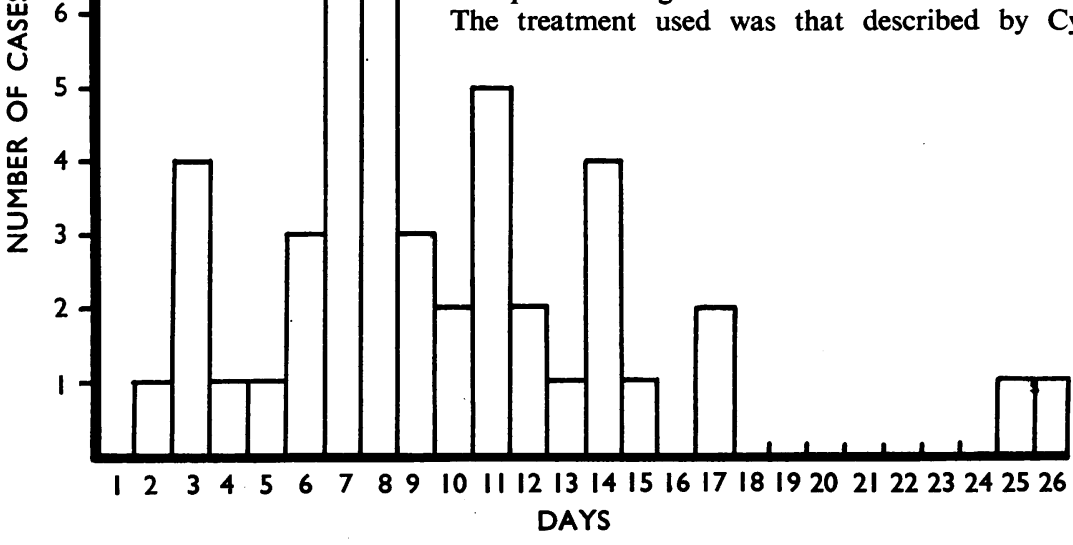

FIG. 1.-Diagram of cases cured showing number of days required, including week-ends, from the onset of treatment.

(1947) for long tendons with a sheath. It consists of deep frictions being given transversely throughout the affected area while the tendon is held taut. Thus, for the most usually affected tendon of the extensor carpi 
radialis the wrist was held in full palmar flexion with ulnar deviation and deep friction was applied across the tendon in its full length for approximately 10 minutes. This period normally preceded or followed a similar one of radiant heat, and generally was quite sufficient for both the physiotherapist and the patient.

Treatment was given daily as long as crepitus persisted and with daily or longer intervals afterwards. The results are shown in Figs. 1 and 2.

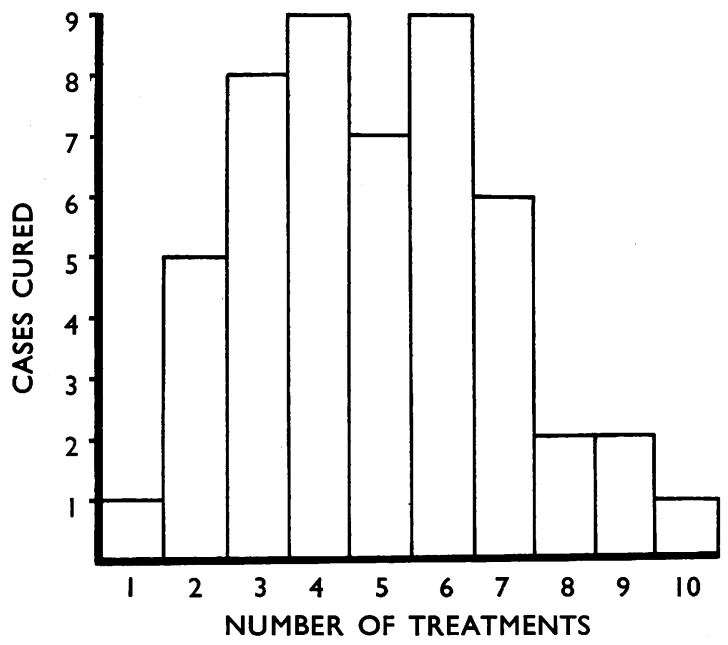

Fig. 2.-Diagram of number of cases cured in relation to the number of treatments.

It will be seen from Fig. 1 that $60 \%$ of the cases could be cleared within eight days of beginning treatment and the large majority within a fortnight. The two cases taking 25 and 26 days respectively were both clinically clear after 10 days. Subsequently one patient went on a fortnight's holiday and the other went on to a period of night shifts. Both when seen again were discharged as cured without further treatment. Shift workers, incidentally, are included in the series, although continuous treatment was of necessity interrupted by the hours of their work.

In three of the 50 cases, certificates asking for light work were sent to the men's departments. The other 47 patients all continued at their normal work, the only ruling being that they were asked to inform the Medical Department if such employment were aggravating the condition. No patient did so report although a few ventured the suggestion that they had found repetitive gripping and lifting caused pain in the affected area.

A few cases are worthy of mention. A bricklayer with bilateral tenosynovitis of the forearm extensors was clear in 13 days during which time he continued at full work, the cause as far as could be ascertained of his original disability. A Mr. C, a well known local squash player, reported with a marked crepitus in, and swelling over, the right tibialis anticus. He was playing squash within five days and was discharged after a week. A workman lifting heavy sheets of plate glass was found to have bilateral tenosynovitis. He responded to treatment within 17 days.

\section{Summary and Observations}

It is felt that where a full-time physiotherapist is available treatment by heat and massage will produce results unobtainable by splinting, and will at the same time enable the workman to continue in most cases to do his normal work. In this respect the results here have differed from the teaching of Cyriax. The following points were noted.

Palpable crepitus could be dispersed at one treatment if the patient could stand it, and could be resolved in all cases after two to three treatments.

Despite the discomfort of the first treatment, no patient failed to keep his next appointment.

Clinically most cases were clear within four to five days and almost every case was clear to the patient's own satisfaction within a fortnight.

In only three cases out of the 50 was the patient's department asked to arrange alternative lighter work. There were no relapses in the series.

We should like to thank our two physiotherapists, Mr. G. F. Moseley, M.C.S.P., and Mr. J. P. Munroe, M.C.S.P., for all their efforts and enthusiasm in connexion with this short investigation.

\section{REFERENCES}

Cyriax, J. (1947). Rheumatism and Soft Tissue Injuries, p. 139. Hamish Hamilton Medical Books, London.

Thompson, A. R., Plewes, L. W., and Shaw, E. G. (1951). British Journal of Industrial Medicine, 8, 150. 